\title{
Unaccusativity as lexical argument reduction: Evidence from aphasia ${ }^{\text {is }}$
}

\author{
Karen Froud* \\ Department of Biobehavioral Sciences, Teachers College, Columbia University, TC Box 180, \\ 525 West 120th Street, New York, NY 10027-6696, United States \\ Received 18 February 2005; received in revised form 30 April 2005; accepted 5 May 2005
}

\begin{abstract}
Theoretical approaches to unaccusativity have placed an emphasis on their derivation from underlyingly transitive predicates, which is assumed to involve argument reduction, possibly triggered by pre-syntactic affixation of some abstract morpheme. This paper presents some data from an aphasic subject who demonstrates a robust effect of grammatical class; he is unable to read any function words, and makes characteristic 'within-category' substitution errors. These errors extend to the class of unaccusative verbs, and this leads to a consideration of the potentially functional nature of the morphological trigger for unaccusativity. Existing accounts of unaccusative deficits in aphasia, and of the likely morphosyntactic representation of unaccusative verbs are discussed. The aphasic deficit, as we understand it, seems to provide evidence in support of the functional determination of unaccusativity.
\end{abstract}

(C) 2006 Elsevier B.V. All rights reserved.

Keywords: Unaccusatives; Aphasia; Morphology; Argument reduction; Functional categories

\section{Introduction and background}

Unaccusativity - the occurrence of a subset of intransitive verbs typically realized with a nonagentive subject - is a key phenomenon in linguistics, because it provides a window on interfaces between components of the language system: unaccusatives have been described as resulting from lexical operations (e.g. Reinhart, 1997) or morphological processes (e.g. Pesetsky, 1995), or

\footnotetext{
The experiments presented here were carried out as part of my dissertation research (completed at University College London in 2001).

* Tel.: +1 212678 3033; fax: +1 2126788233 .

E-mail address: kfroud@tc.columbia.edu.
} 
as being crucially syntactically determined (e.g. Burzio, 1986; Borer, 2004), and/or semantically licensed (e.g. Levin and Rappaport-Hovav, 1995). Unaccusatives been observed to cause difficulties in L1 acquisition (e.g. Snyder et al., 1995; Babyonyshev et al., 2001), L2 learning (e.g. Montrul, 1999; Oshita, 2001; Sorace and Shomura, 2001), and in cases of acquired language disorder (e.g. Kegl, 1995; Thompson, 2003). All this has led to some interesting and important theorizing on the subject of unaccusatives, in various attempts to capture their properties. In particular, the observation that many unaccusatives also have transitive alternations (see (1)-(4)) has prompted proposals about the nature of the argument structure change that determines the surface realization of verbal predicates. For instance, Reinhart $(1997,2000)$ has suggested that unaccusatives are derived from transitives by the same process that determines reflexives: argument reduction, an operation which applies to the internal argument of a transitive to yield a reflexive, and to the external argument to yield an unaccusative. Pesetsky (1995), in contrast, proposed that suppression or elimination of an argument is due to abstract affixation of one of a small set of argument-structure-changing morphemes to the verbal predicate. Examples of these alternations between transitive and unaccusative realizations are provided in (1)-(3), in contrast with (4) which illustrates the unergative (or intransitive) verbal predicates whose single argument can be interpreted as an Agent:

$\begin{array}{ll}\text { Transitive: } & \text { Zach bounced the ball. } \\ \text { Unaccusative: } & \text { The ball bounced. } \\ \text { Transitive: } & \text { The sunlight wilted the flowers. } \\ \text { Unaccusative: } & \text { The flowers wilted. } \\ \text { *Transitive: } & \text { *The acid rain died the flowers. } \\ \text { Unaccusative: } & \text { The flowers died. } \\ \text { Unergative: } & \text { Josh jumped. }\end{array}$

Questions remain as to the precise nature of the process whereby unaccusative verbs are derived from related transitive predicates; in particular, how unaccusativity is triggered, and whether any (abstract or otherwise) morphological reflex of this process can be identified. It has often been observed that the external argument of an unaccusative predicate is not simply suppressed; by any standard diagnostics of agentivity, the external argument of an unaccusative is completely eliminated (discussed further). An economical way to capture this observation could be that unaccusative predicates result from lexical suppression of the internal theta role of an underlyingly transitive verb, which may result from adjunction to some functional head. Such a view, however, raises the possibility that unaccusative verbs are identified with functional categories at some level of representation, a possibility which, given the underdetermination of the lexical/functional distinction in current formulations of syntactic theory, cannot easily be supported or definitively ruled out.

The current paper speaks to this question, first by providing an overview of some theoretical developments concerning the representation and derivation of unaccusative predicates, and then by presenting some data from an investigation of the reading of unaccusative (and other) verbs in a case of acquired language disorder.

The use of data from investigations of language disorder (of various kinds) as evidence in linguistic theory is still less standard than the use of intuition data (but see, e.g. Jakobson, 1956; Grodzinsky, 1990 - important examples of many attempts to use aphasic data in the evaluation of 
competing linguistic theories). Whilst recognizing the reasons for this reliance on intuitions as data in linguistic research, which is a response to the mentalistic nature of the object under investigation (Chomsky, 1965), I take the view that in linguistics, as in any empirical field, all data that speak to an issue can be evaluated independently of their source. The relationship between linguistic theory and language pathology is beginning to fulfill its early promise of bi-directionality: the theoretical frameworks are crucial for appropriately detailed analyses of clinical language impairment, and these detailed analyses are finally making it possible for linguistic theory to be informed by data from language pathology.

For the purposes of the current paper, what is needed to evaluate the functional status of unaccusatives is an aphasic subject who demonstrates a very robust dissociation between functional and substantive categories, in at least one performance modality. The aphasic subject MC provided such a testing opportunity, in the single-word reading modality, because he was totally unable to read any functional items (including determiners, complementisers, quantifiers, inflectional elements, wh-words, pronouns, negation and conjunctions) in sharp contrast with his relatively intact reading of substantives (Druks and Froud, 2002; Froud, 2001a,b). MC has already provided opportunities to investigate the lexical/functional status of various categories, including adverbials (Froud, 2001a) and prepositions (Froud, 2001b). In what follows, I will first briefly outline some current theoretical accounts of unaccusativity, and show how these perspectives point to a view of unaccusatives as (associated with) functional heads. Next, I describe in more detail MC's lexical/functional dissociation, and present an experiment designed to establish whether he ever treated unaccusative verbs as functional heads. Finally, I return to the theoretical accounts of unaccusativity, and consider whether MC's performance (a) can be accounted for under such views, and (b) can provide supporting evidence concerning the functional representation of unaccusative verbs.

\section{The derivation of unaccusative verbs}

\subsection{Unaccusativity as argument reduction}

It has been suggested that the representation of unaccusative verbs necessarily requires some kind of lexical derivation, since many verbs with a surface unaccusative realization are underlyingly related to transitive predicates. This derivational view of unaccusativity was made explicit in accounts by Reinhart $(1997,2000)$ and Pesetsky (1995), who have both taken the view that unaccusativity results from a lexical operation which suppresses (or eliminates) the agent of the corresponding transitive realization of the verb. Reinhart $(1997,2000)$ discusses reduction as a process by which one argument of a two-place predicate is 'bound' to the other (similar to Grimshaw's 1990 'lexical binding'). Reduction of the internal argument of a predicate results in reflexivization:

$$
\begin{array}{ll}
\mathrm{R}(\text { wash })\left(\theta_{1}\right) \quad \begin{array}{l}
\text { Zak washed } \\
(=\text { Zak washed Zak })
\end{array} \theta_{1}=\theta_{2}
\end{array}
$$

Unaccusative syntax results from reduction of the external argument; however, according to Reinhart, this must apply to a more complex abstract verb which involves a causal relationship ((6)a-c, based on Reinhart's (1997) (16) and (17)): 

a. roll $<\theta_{1}, \theta_{2}>$
Josh rolled the stone
b. Reduction of internal argument:
$\mathrm{R}$ (roll) $\left(\theta_{1}\right)$
c. Reduction of external argument:
Josh rolled (in order to impress us) $\theta_{1}=\theta_{2}$
$\mathrm{R}_{\mathrm{i}}$ (roll) $\left(\theta_{2}\right)$
The stone rolled (i.e. a property of the stone caused the stone to roll)
$\theta_{2}=\theta_{1}$

This account is not unproblematic, however. In particular, Reinhart's account does not capture the differences between unaccusatives and reflexives, though it does unify the observed similarities between the two (both can be underlyingly transitive, both realize one argument but suppress or eliminate the other). The main difference is that the internal argument of a reflexive can be overtly realized as an anaphor bound by the external argument. The bound external argument of an unaccusative, by contrast, is not accessible for surface realization:
a. Zak washed.
b. Zak washed himself.
c. Josh arrived.
d. *Josh arrived himself.
e. $\quad *$ He arrived Josh.

(7d) is out because the anaphor occupies the internal argument position, and is therefore the only argument receiving a theta role from the verb. Since the verb is unaccusative, this means that Josh in external argument position cannot be theta-marked; since there is no chain between the Agent and the anaphor, there is a Theta Criterion violation. ${ }^{1}$ (7e) is out for similar reasons; the pronominal subject does not need to be bound, but it cannot receive a theta role because the single theta position is occupied by Josh. There is no possibility for the realization of the external argument of an unaccusative verb. This suggests that, whatever happens to an underlyingly transitive verb to yield unaccusative syntax, it is a qualitatively different process to reflexivization. The external argument of an unaccusative verb is not just bound or reduced, but is actually eliminated from the verb's representation.

Reinhart and Siloni (2004) build on Reinhart's earlier accounts to provide a unitary picture of cross-linguistic variation in the properties of reflexive predicates. They discuss lexical versus syntactic internal argument reduction, suggesting that lexical reduction forms an unergative entry (from a transitive entry), with one Case feature and one theta role to assign. Syntactic ${ }^{2}$ lexical reduction, however, results in removal of one Case feature, but no corresponding reduction in the number of theta roles the verb must assign. The appropriate numeration must contain only one realizable DP, because only one Case feature remains, and the two theta roles must both be assigned to that same DP. ${ }^{3}$ This results in a reflexive interpretation for the verbal predicate. Since unaccusativity results from reduction of the external theta role, this must be an instance of lexical application of the reduction operation. ${ }^{4}$

\footnotetext{
${ }^{1}$ Not to mention a Principle A violation; the anaphor is not bound by John because John is not in an argument position.

2 Actually they propose that reduction can hold at LF.

${ }^{3}$ Reinhart and Siloni assume, with Chomsky (1995) and Reinhart and Reuland (1993), amongst others, that the Theta Criterion "is not indispensable" (p. 177).

${ }^{4}$ Syntactic reduction of the external theta role could possibly result in the middle construction-but I do not have the space to pursue that proposal here.
} 
I turn now to a consideration of the mechanism for argument reduction, from a slightly different perspective.

\subsection{Argument-structure-changing morphemes}

In Pesetsky's (1995) discussion of zero morphemes, he assumes the existence of a small repertoire of bound morphemes with null phonological realizations, which have varying effects on the argument structure of the verbs to which they attach. Pesetsky argues that these morphemes are part of UG; they are universally available, and only parametrically variant in terms of whether or not they are assigned an overt realization. Features associated with these heads, on Pesetsky's account, can be strong or weak (a property of functional heads, per Chomsky, 1995). Given these properties, it makes sense to assume that these heads are functional-phonetically null or not, they are part of the UG lexicon, have Strength as a property of their features, and are the locus of parametric variation. ${ }^{5}$

Pesetsky's zero morphemes have various effects on the argument structure of the verbal predicates to which they are affixed. Much of Pesetsky's discussion focuses on the head he calls CAUS, which, when it attaches to a verb, has the property of introducing a thematic Causer to the predicate and/or suppressing the external theta role of the verb. As he points out, if some such process also applies to unaccusatives, this would account for the often-observed fact that unaccusatives generally cannot be passivized:

a. The train disappeared over the horizon.

b. $\quad *$ The horizon was disappeared over (by the train).

a. Zak trembled under the stern gaze of the professor.

b. $\quad *$ The stern gaze of the professor was trembled under (by Zak).

The external argument of the unaccusative has already been absorbed, presumably by affixation of some other abstract morpheme, leaving no Agent role to be assigned to the passive morphology. This would lead to a violation of the Theta Criterion, since effectively the passive morpheme is an argument, so must receive a theta role (cf. Baker et al., 1989; Jaeggli, 1986).

In the spirit of the analyses I have outlined here, I propose the existence of some functional head with a null phonological realization, to which verbs may be adjoined at some pre-syntactic level of representation (presumably lexical). Like Pesetsky's CAUS, this functional head absorbs an external argument, resulting in argument reduction, but remaining crucially distinct from CAUS because no causative reading is imposed on the semantics of the verb. Under the view I am proposing, an unaccusative can be assumed to have an underlying (lexical) representation which is the same as that for a transitive verb, with positions for internal and external arguments. But a verb which has an obligatorily unaccusative realization has a requirement, sometimes conceived of as a diacritic on the lexical entry, which forces its adjunction to this particular

\footnotetext{
${ }^{5}$ Pesetsky characterizes his zero argument-structure-changing morphemes as derivational, rather than functional; however, as suggested, on a view of the language faculty as incorporating a psychologically real dichotomy between substantive and functional categories, heads with these properties would certainly qualify as functional.
} 
argument-structure-reducing ('unaccusativizing') morpheme before it can enter the syntactic derivation. Perhaps such verbs are lexically 'frozen' in their unaccusative state (Reinhart, 1997; but see section 4.2 for further discussion of this question). In any case, lexical reduction of the external argument, under my proposal, involves adjunction of a transitive verb to a functional head before the verb enters the numeration.

\subsection{Unaccusatives as (adjoined to) functional heads}

There is some independent evidence that unaccusatives could be considered as functional heads, in the sense that they are adjoined to a (phonologically null, in English) functional head prior to entering the computational component. I have already discussed that the overt versus covert phonological realization of an argument-structure-changing morpheme suggests that such morphemes are loci of parametric variation, a property of functional heads. Additionally, they may show parametric variation in the semantic domain. For example, the well-known observation that there is cross-linguistic variation in the semantic 'trigger' for unaccusativitystativity in Italian, telicity in Dutch, and so on (e.g. Sorace, 1995, 2004) could be traced back to the possible nature of the 'diacritic' I have hypothesized to trigger adjunction of $\mathrm{V}$ to the hypothetical unaccusativizing morpheme; some semantic feature could trigger adjunction to a functional head. Borer (2004) has also argued that unaccusative syntax may be the reflex of the presence of aspectual heads which project in the syntax and assign interpretations to the arguments of the verbs associated with those structures; the interpretation of the verbal predicate itself is a combination of its specific lexical-conceptual structure plus the interpretation(s) of its independently licensed argument(s). In other words, unaccusativity is indeed syntactically realized, but is dependent on Selection (and adjunction) of the relevant functional head at a pre-syntactic level. ${ }^{6}$

If the analysis I have presented here is along the right lines, it is possible to make some predictions about the availability of unaccusative verbs to individuals with particular patterns of acquired language disorder. Specifically, what is needed is an aphasic subject who makes a reliable distinction between lexical and functional categories; this distinction could be exploited to examine the representation (for that individual) of unaccusative verbs. Lexical/functional distinctions are not unusual in the aphasiology literature, especially since one of the defining characteristics of agrammatic aphasia is standardly assumed to be a deficit affecting 'function words' (e.g. Howard, 1985; Marshall, 1986; Grodzinsky, 1990 and many others). In the next section, I describe the unusually robust lexical/functional distinction which has been demonstrated in a particular aphasic subject, MC (Druks and Froud, 2002; Froud, 2001a,b), and present an experimental investigation of his representation of unaccusative verbs.

\footnotetext{
${ }^{6}$ The account of unaccusativity I have put forward so far stresses the functional nature of the proposed unaccusativizing morpheme, and the productivity of unaccusativization for underlyingly transitive verbal predicates. However, it does not capture the unavailability of a transitive alternation for some verbs. I have no solution to this at present, though to speculate, it may be that the presence or absence of a transitive alternation in a particular language may depend on the relative strength or weakness of features of the relevant functional head; or on the strength of the semantic trigger for unaccusativity. Perhaps unaccusativity is a graded phenomenon, which could mean that the presence of more than one of the semantic features thought to trigger unaccusative syntax makes it more difficult to override the requirement for the verb to be pre-syntactically adjoined to the unaccusativizing morpheme.
} 


\section{An investigation of unaccusative verb reading in a case of acquired language disorder}

\subsection{Subject}

MC was a right-handed male who suffered a left hemisphere embolic CVA in 1990. At the start of the investigations described here, he was aged 74 years and was 10 years post-CVA. Prior to his stroke, MC was a successful opera impresario. The CVA left him with a right-sided hemiplegia which confined him to a wheelchair.

MC has already provided some unusual opportunities to increase understanding of certain linguistic constructs because of the unusually pure patterns of dissociation he demonstrated in single word reading tasks with regard to lexical versus functional categories. MC did not only have difficulties in reading; in fact he had multiple aphasic deficits, and his problems with morphological representations and function word realization had complex effects on his language performance in all modalities. His profile on the Boston Diagnostic Aphasia Examination (Goodglass and Kaplan, 1972) was most similar to that of a Broca's aphasic, but he had access to a wider range of grammatical structures than a typical Broca's aphasic, and his articulatory agility was less impaired (MC's BDAE profile, and details of many aspects of MC's language abilities which I only touch on here, are provided in Druks and Froud, 2002). Testing showed that MC's naming ability was moderately impaired (Boston Naming Test Kaplan et al., 1983: 48/60 (80\%) correct; Object and Action Naming Battery (Druks and Masterson, 2000: 108/ $140(77 \%)$ actions and 129/140 (92\%) objects named correctly).

I focus here on MC's single word reading for several reasons. In single word reading tasks, MC demonstrated a profoundly compromised ability to read any functional items, including auxiliary verbs, complementizers, conjunctions, determiners, negation, pronouns, quantifiers, and wh-words. This dissociated robustly from his spontaneous speech, in which he was able to use many of the same functional categories appropriately in a wide range of syntactic structures, and from his reading of substantives, which remained relatively intact (extending even to substantive words of low frequency and/or imageability: for example, on PALPA subtest 31 (Kay et al., 1992), MC read 30/40 (75\%) of high frequency words correctly, and 26/40 (65\%) low frequency words; of high imageability words, 30/40 were read correctly, compared to 27/40 low imageability words. His high error rate overall on this task was largely due to his tendency to add an indefinite article to the bare nouns, rather than to errors on the target words themselves). Additionally, we have demonstrated that MC's comprehension of written function words in isolation was intact (so far as this is possible to test); so that he recognized functional items, and knew what they meant, even when he was completely unable to read them (Druks and Froud, 2002). MC's ability to produce these same categories in connected speech was hypothesized to be supported by the availability of lexical information for substantives, presumably including their extended projections, so that production of functional categories in connected speech, or in a sentential context, or in reading of connected text, is bolstered by the availability of the syntactic frame. Single word reading tasks were found to be the most effective way of forcing $\mathrm{MC}$ to produce function words in isolation, since this task results in removal of the syntactic frame within which function words are more usually located — and which, for MC, provided support for their realization.

In single-word reading tasks, MC demonstrated particularly robust distinctions between lexical and functional categories, across many more items than are usually reported in cases of so-called function-word breakdown (detailed below; for examples and discussion of previously 
reported cases, and a comparison of the number of data points provided between those cases and that of MC, see Froud, 2001b). He also very rarely failed to respond, even to words he could not read; he would almost always make the attempt. This has meant that, in contrast with subjects who 'don't know' or do not respond at all to items they find difficult, detailed error analysis has been possible in the case of MC. And this error analysis has shown that the errors MC made when reading functional categories were distinct from errors he made on substantives (which, as well as being far less frequent, tended to be visual, phonological, or - mainly - morphological in nature): when presented with a functional category to read, MC substituted another functional item for the target word, which he never did for any other category.

Examples of substantives and function words presented to $\mathrm{MC}$, and his responses when he attempted to read them, are provided in Table 1 (data from Froud, 2001b).

Table 1

Examples of MC's reading of substantive and function word reading (data from Froud, 2001b)

\begin{tabular}{|c|c|c|}
\hline Error type & Target & MC's response \\
\hline \multicolumn{3}{|l|}{ Morphological } \\
\hline \multirow[t]{2}{*}{ Inflectional } & mortgage & mortgages \\
\hline & prove & proven \\
\hline \multirow[t]{2}{*}{ Derivational } & aunt & auntie \\
\hline & happy & happiness \\
\hline Inflectional and derivational & earn & earnings \\
\hline \multirow[t]{4}{*}{ Visual or phonological } & circuit & circus \\
\hline & subtle & substitute \\
\hline & lever & levity \\
\hline & daze & haze \\
\hline \multirow[t]{2}{*}{ Semantic } & Motor & Car \\
\hline & Hear & Listen \\
\hline \multirow[t]{17}{*}{ Function word substitutions } & whether & before or because \\
\hline & that & after, I don't know \\
\hline & all & for \\
\hline & some & after, I don't know \\
\hline & any & because \\
\hline & the & at \\
\hline & this & for or to \\
\hline & you & before or because \\
\hline & yourself & after or nobody \\
\hline & 1 & one $\ldots$ no, because or and \\
\hline & him & and $\ldots$ before \\
\hline & then & before or because \\
\hline & can & because \\
\hline & could & before or because \\
\hline & have & it is ... about? \\
\hline & because & after \\
\hline & and & because \\
\hline
\end{tabular}

Across many different reading lists, presented over several years of testing, MC made 546 (79.83\%) function word substitution errors out of 684 occasions of attempting to read function words. He got only 83 correct $(12.13 \%)$, and either failed to respond or produced an unrelated 
substantive on the other occasions. His reading of substantives (nouns, verbs and adjectives), by contrast, resulted in $84.31 \%$ correct performance (661 words read correctly out of a possible 784 ), with the majority of his errors involving affix substitution, omission or insertion. None of his errors on reading of substantive items consisted of a function word substitution. These data provide a much stronger case for a functional/substantive dissociation than others reported in the aphasiology literature (e.g. Biassou et al., 1997; Patterson, 1982; Friederici and Schoenle, 1980; Morton and Patterson, 1980), in terms of the robustness of the separation between categories, the qualitative distinction in error types, and the sheer number of observations.

\subsection{Materials and methods}

The current investigation examined MC's single word reading of unaccusative verbs. I have already observed that single word reading, in MC's case, was the task which provided the clearest insight into his (dis)abilities in the morphosyntactic representation of particular categories. Unaccusatives, however, are useful for single word reading tasks in another way too. Many verb alternations are only available when the verb is presented within a sentence frame, and we have shown that presentation of words in sentential contexts supported MC's ability to produce and interpret them to the point that no clear analysis of his real representations was possible. For instance, a passive (in English) typically carries the same inflection as a past tense verb in the active voice:
a. Active
Josh tickled Zak.
b. Passive
Zak was tickled by Josh.

So presenting a passive verb in isolation is not helpful, because it is not unambiguously passive. This similarly holds with other argument structure alternations; middles, causatives and reflexives, for instance, are only identifiable as such within a particular (surface) syntactic frame which is the reflex in the computational component of their morphological properties. Unaccusatives, however, are exceptional in this regard. A (non-alternating) unaccusative verb remains unaccusative, even when presented in isolation; and in English it need not bear any overtly realized affixation.

A reading list was prepared for MC which comprised four conditions. Firstly, there were 25 unaccusative verbs with no transitive alternation (e.g. depart, ensue), and 50 unaccusative verbs with a transitive alternation (e.g. bounce, hang). Secondly, 25 intransitive verbs (e.g. cringe, meditate, complain) were included. Finally, 25 transitive verbs with no unaccusative alternation (e.g. worship, declare, adjudicate) were added to the list. All the verbs included in the list were presented as bare (uninflected) stems, so attempts were made to include only those verbs which are not orthographically identical to other word classes. ${ }^{7}$ Lexical frequency was controlled, using the CELEX database (Baayen et al., 1995), so as to be able to rule out the possibility that MC would make function word substitution errors on so-called 'non-specific' words (Funnell, 1983); that is, verbs which may be very difficult to 'activate' because they are used very infrequently in the language. Mean frequency ratings are presented in Fig. 1.

Both classes of unaccusatives had significantly higher lexical frequencies than the other verb types ( $t$ statistics calculated assuming unequal variance: alternating unaccusatives versus

\footnotetext{
${ }^{7}$ This was not completely possible, however, since many of these verbs can be construed as deverbal nominals given an appropriate context.
} 


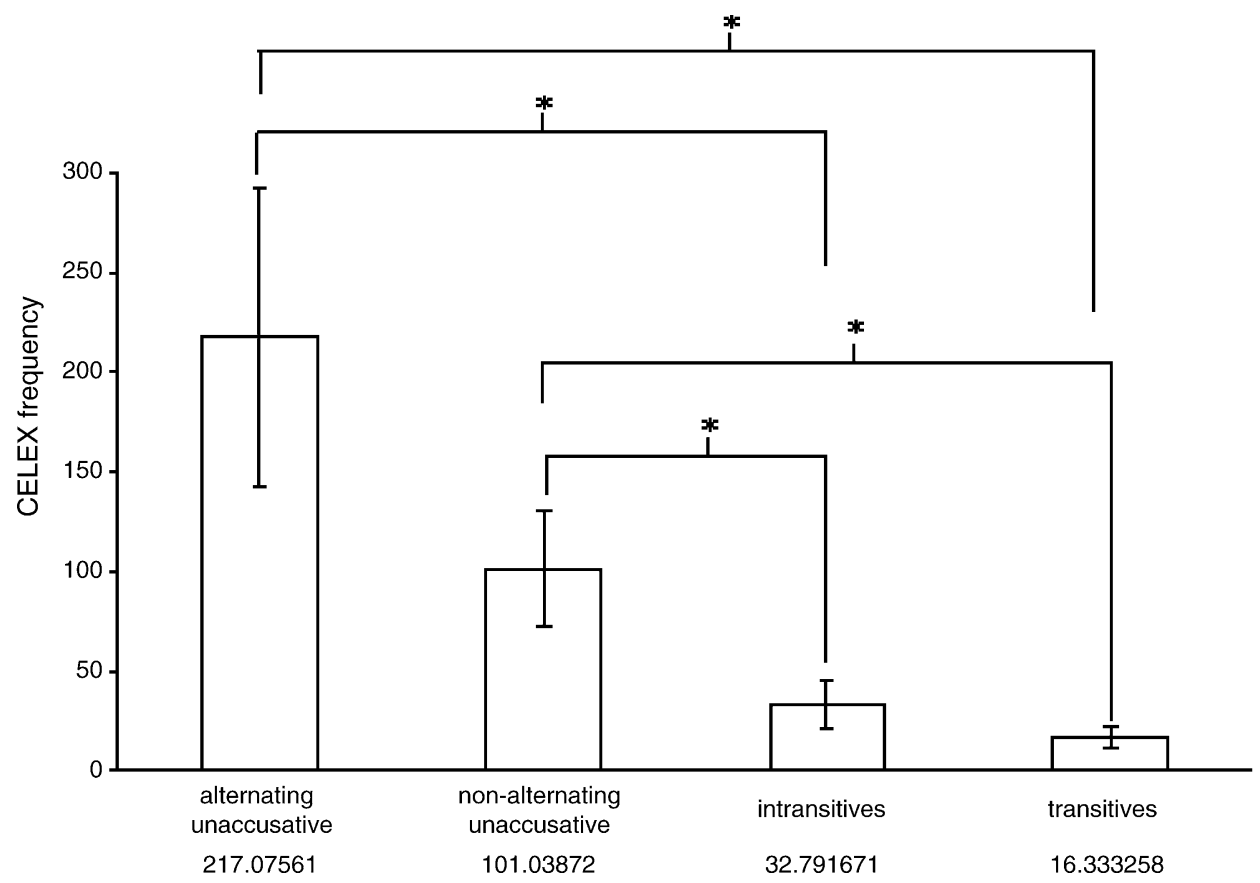

Fig. 1. Mean lexical frequency for verb classes included in the reading list (means are reported under each category label). An asterisk indicates a significant difference between groups $(p<0.05)$. Error bars show standard error of the mean.

intransitives, $t(51.54)=2.427, p=0.019$; alternating unaccusatives versus transitives, $t(49.408)=2.673, p=0.01$; non-alternating unaccusatives versus intransitives, $t(32.368)=$ $-2.196, p=0.035$; non-alternating unaccusatives versus transitives, $t(25.376)=-2.921$, $p=0.007$ ). It was thought that this should make the unaccusative verbs easier (if anything ${ }^{8}$ ) for $\mathrm{MC}$ to process, biasing against the hypothesis that he was more likely to misidentify these words as functional categories (which are more difficult for him to read than substantives).

Imageability ratings were not available for most of the verbs selected for these reading lists. For the two lower-frequency categories (intransitive and transitive verbs), imageability ratings were obtained on a 1-7 scale ( 1 for very low imageability, 7 for very easily imageable) from 12 graduate students. The transitive verbs were reliably rated as being of lower imageability than the intransitive verbs (mean (S.D.) for transitive verbs: 3.4667 (0.79203); for intransitive verbs: $5.1867(0.26672) ; t(48)=5.545, p<0.001)$.

Accordingly, the reading list prepared for $\mathrm{MC}$ had the following properties. The alternating and non-alternating unaccusative verbs were of higher frequency than the transitive and intransitive verbs. The transitive verbs were of low frequency and were rated as being less imageable than the intransitive verbs. There were 125 verbs in the list altogether. The presentation order was randomized and all the verbs were printed in black on white paper, in 24-point font (a size which MC was accustomed to reading in other experimental tasks), with 12 words to a page, one word on each line. Words were presented one at a time by using a card

\footnotetext{
${ }^{8}$ Recall that MC has been shown not to be reliably affected in single-word reading tasks by frequency and/or imageability (see earlier discussion of MC's language abilities; more detail is available in Druks and Froud, 2002).
} 
mask, moved by MC so that he could set his own reading pace. The list was presented to MC for reading on five separate occasions (using five different random presentation orders), to generate more data. The reading attempts were separated by at least three months to avoid priming and practice effects.

\subsection{Predictions}

If MC's reading was primarily being affected by psycholinguistic factors such as imageability and frequency, then the intransitive and transitive verbs were predicted to be much harder for him to read than those verbs with the availability of an unaccusative reading. If, however, the primary factor which made words difficult for MC in single word reading tasks was their morphosyntactic complexity, then the alternating and non-alternating unaccusative verbs should have been more difficult for MC to read. The third possibility, and perhaps the most likely, was that these factors would interact, resulting in an even spread of error rates for MC between the different verb categories; however, and crucially, because of MC's particular pattern of performance, different patterns of errors were expected to be apparent in his attempts to read these verbs. If the unaccusatives are, as hypothesized, lexically associated with functional heads, then MC's characteristic function word subsititution errors were expected to appear in response only to verbs in the alternating and non-alternating unaccusative categories. All categories were expected to result in other kinds of errors, including morphological (derivational and inflectional) and visual errors, which were frequently observed in his reading of all word classes (see Table 1).

\subsection{Results}

Results of MC's five attempts at reading this verb list are summarized in Table 2.

Table 2

Results of the verbs reading task

\begin{tabular}{|c|c|c|c|c|c|c|c|c|c|c|}
\hline & \multicolumn{2}{|c|}{$\begin{array}{l}\text { Unaccusatives } \\
(n=25 \times 5)\end{array}$} & \multicolumn{2}{|c|}{$\begin{array}{l}\text { Alternating } \\
\text { unaccusative/ } \\
\text { transitives } \\
(n=50 \times 5)\end{array}$} & \multicolumn{2}{|c|}{$\begin{array}{l}\text { Intransitives } \\
(n=25 \times 5)\end{array}$} & \multicolumn{2}{|c|}{$\begin{array}{l}\text { Low imageability/ } \\
\text { frequency } \\
\text { transitives } \\
(n=25 \times 5)\end{array}$} & \multicolumn{2}{|c|}{$\begin{array}{l}\text { Totals } \\
(n=125 \times 5)\end{array}$} \\
\hline & $n$ & $\%$ & $n$ & $\%$ & $n$ & $\%$ & $n$ & $\%$ & $n$ & $\%$ \\
\hline Correct & 87 & 69.6 & 200 & 80 & 84 & 67.2 & 90 & 72 & 461 & 73.76 \\
\hline \multicolumn{11}{|l|}{ Errors } \\
\hline $\begin{array}{r}\text { Function word } \\
\text { substitutions }\end{array}$ & 15 & 12 & 24 & 9.6 & 0 & 0 & 0 & 0 & 39 & 6.24 \\
\hline Derivational errors & 5 & 4 & 8 & 3.2 & 15 & 12 & 5 & 4 & 33 & 5.28 \\
\hline Inflectional errors & 9 & 7.2 & 8 & 3.2 & 9 & 7.2 & 2 & 1.6 & 28 & 4.48 \\
\hline \multicolumn{11}{|l|}{ Subsitution errors } \\
\hline Phonological/visual & 7 & & 7 & & 12 & & 22 & & 48 & \\
\hline Semantic & 1 & & 0 & & 0 & & 1 & & 2 & \\
\hline All substitution errors & 8 & 6.4 & 7 & 2.8 & 12 & 9.6 & 23 & 18.4 & 50 & 8 \\
\hline Other/unrelated errors & 0 & 0 & 2 & 0.8 & 4 & 3.2 & 1 & 0.8 & 7 & 1.12 \\
\hline No response & 1 & 0.8 & 1 & 0.4 & 1 & 0.8 & 4 & 3.2 & 7 & 1.12 \\
\hline Total errors & 38 & 30.4 & 50 & 20 & 41 & 32.8 & 35 & 28 & 164 & 26.24 \\
\hline
\end{tabular}


There were some difficulties in error classification. The decision as to whether a morphological error should be counted as derivational or inflectional was somewhat arbitrary. Some were obvious: for example, MC produced dine as 'dinner', resolve as 'resolute', thrive as 'thrift'; all such errors clearly involved derivational affixation. Some affixation errors less clearly resulted in word class changes (they could have been counted as gerunds, or gerundives, for example) but these have been counted as errors of inflectional affixation. These include: happen read as 'happening', live read as 'living', recover read as 'recovered'. One similar instance was counted as a derivational error, because MC appeared to treat the resulting word as a noun-he read begin as 'beginning or end'. Some were even less obvious; for instance, MC read pant as 'pants' on two occasions. This could either mean that he treated the verb as nominal, with a plural inflection, or that he inflected the verb with a third person agreement marker. These errors were also counted as inflections, but notice that a word class change may have been present. Two responses involved affix omission (justify was read as 'just', symbolize as 'symbol') and these were counted as derivational errors. A few responses seemed to involve multiple morphological errors: for instance, cower was read on one occasion as 'cowing', which involved omission of the -er (which may be affixal or lexical-the relationship between cow and cower in morphological terms not being very easy to determine) and inflection with-ing. This response was scored as an inflectional error, though it may have had a visual element. Some other errors were more clearly visual in nature, and when the morphological relationship was not readily determined, this was how they were scored-for instance, MC read vaporize as 'evaporate'. Phonological and visual errors can also be difficult to distinguish from one another, and $\mathrm{MC}$ also had difficulties with pronunciation at times (due to a mild oral dyspraxia) which complicated matters. Pronunciation errors due to the dyspraxia were counted as 'other', since they could not be classified as correct yet they do not reflect language-internal processes like affixation. Phonological errors were only recognized if the response differed from the target by one phonetic feature (e.g. he twice read crumple as 'crumble'); otherwise, such mistakes were classified as visual errors (e.g. alleviate read as 'deviate', meditate as 'mediate'). For analysis, phonological and visual errors were counted together (reflected in table two); additionally, because there were so few semantic errors in MC's responses, semantic errors were added into this broader category of 'substitution errors'.

Analyses confirmed that there were no reliable differences in MC's overall performance across the five trials. MC read 23 of the 50 alternating unaccusative/transitive verbs correctly on all five occasions of testing. He read a further 12 correctly four out of five times, 12 three out of five times, and 3 (recover, know and vaporize) were read correctly only once. He failed to read begin correctly at all, making four function word substitution errors and one derivational error on this item. ${ }^{9}$

Overall, MC was correct on $80 \%$ of the alternating class, collapsing across all five testing sessions. In this category, MC made a total of $24(=9.6 \%)$ function word substitution errors (all the function word substitution errors made on this reading list are provided individually in Table 3). Nine of his errors were derivational (e.g. advance $\rightarrow$ 'advancement', choke $\rightarrow$ 'choker'), seven inflectional (e.g. dangle $\rightarrow$ 'dangling', grow $\rightarrow$ 'growing'), and he made seven phonological or visual errors (e.g. split $\rightarrow$ 'spit', crumble $\rightarrow$ 'crumple').

\footnotetext{
${ }^{9}$ Attempts to identify or define some feature which made certain verbs within a verb category apparently more (or less) vulnerable to a particular error type have not so far been successful (for example, the 23 alternating unaccusative verbs which MC read correctly did not have higher or lower frequency ratings than the others in that category).
} 
Of the non-alternating unaccusatives, 7 of the 25 were read correctly on all five presentations (blush, die, arise, persist, perish, depart and prevail). MC read six correctly on four out of five occasions, nine were read correctly three times, and 1 (thrive) was read correctly twice. He failed to respond correctly on any occasion to remain and happen (making five function word substitutions on the former, and five inflectional errors on the latter). Overall, he was correct on $69.6 \%$ of all nonalternating unaccusatives across all five testing sessions. He made 15 function word substitution errors, five derivational errors (e.g. deteriorate $\rightarrow$ 'deterioration', reverberate $\rightarrow$ 'reverberation'), and nine inflectional errors (e.g. tremble $\rightarrow$ 'trembling', glisten $\rightarrow$ 'glistening'). Other errors were visual (e.g. vanish $\rightarrow$ 'vanquish') and unrelated/no response. MC made one semantic error in this class (glisten $\rightarrow$ 'glitters').

MC made no function word substitution errors at all on any of the other verb classes tested. Errors on the intransitive verbs were mainly derivational (e.g. convalesce $\rightarrow$ 'convalesecent'; agree $\rightarrow$ 'agreement'), and on the transitive verbs he made mostly visual errors (e.g. confute $\rightarrow$ 'confuse'; attain $\rightarrow$ 'attend'). He correctly read $67.2 \%$ of the intransitives and $72.0 \%$ of the transitive verbs.

A one-way ANOVA (comparing the proportion of each error type for each item) confirmed that there was no significant difference in the number of errors made by $\mathrm{MC}$ in response to the different verb classes $(F(3,121)=1.696, p=0.171)$. The transitive verbs with low frequency and low imageability resulted in slightly more errors overall, including more failures to respond and more substitution errors (though none of these effects reached significance). A few more derivational errors were made in response to the intransitive verbs than any other verb category, but this only reached borderline significance $(F(3,121)=2.730, p=0.047)$. Reliable effects found in this comparison concerned the proportion of function word substitution errors $(F(1,121)=4.648,=0.004)$ and the proportion of other substitution errors $(F(1,121)=5.050$, $p=0.002$ ). Planned comparisons confirmed that the proportion of function word substitution errors in response to both categories of unaccusative verbs compared to the absence of such responses in the other verb categories was highly significant (alternating unaccusatives versus intransitives and versus transitives: $t(49)=3.645, p=0.001$; non-alternating unaccusatives versus intransitives and versus transitives: $t(24)=-2.683, p=0.013$ ). The effect of other substitution errors was found to be due to the greater proportion of such errors in response to the transitive verbs compared with the alternating $(t(27.536)=-3.171, p=0.004)$ and nonalternating $(t(34.067)=2.287, p=0.028)$ unaccusative verbs.

\section{Discussion of results}

The result that MC made function word substitution errors only on those verbs with an unaccusative reading, and absolutely no such errors on the other verb classes, suggests that $\mathrm{MC}$ can at some level identify and respond to unaccusativity, but generating the structure associated with the syntactic reflex of unaccusativity is problematic for him and sometimes leads to his misidentification of an unaccusative verb as a functional category. Because MC's lexical/functional distinction has been shown to be so robust, we are provided with an opportunity to consider what property of unaccusative verbs MC's function word substitution errors reflect.

Table 3 shows all the function word substitution errors made by MC on reading the unaccusative verbs. It can be seen that there is a predominance of a few function words, MC's 'favourites', with the majority being conjunctions (especially before, because, and and) and prepositions (for, at, on). No particular response is significantly predominant, and MC does not appear to use visual or semantic cues to help him decide which function word he will produce 
(reading know as 'how' could possibly be an exception to this). Most of the target words did not meet with the same responses on different occasions (though a few occurred twice-e.g. begin $\rightarrow$ 'because'; recover $\rightarrow$ 'because'); indeed, the variability is surprising, with the verb remain receiving five different functional category substitutions on the five separate attempts.

Table 3

All of MC's function word substitution errors on verbs in the unaccusatives reading list

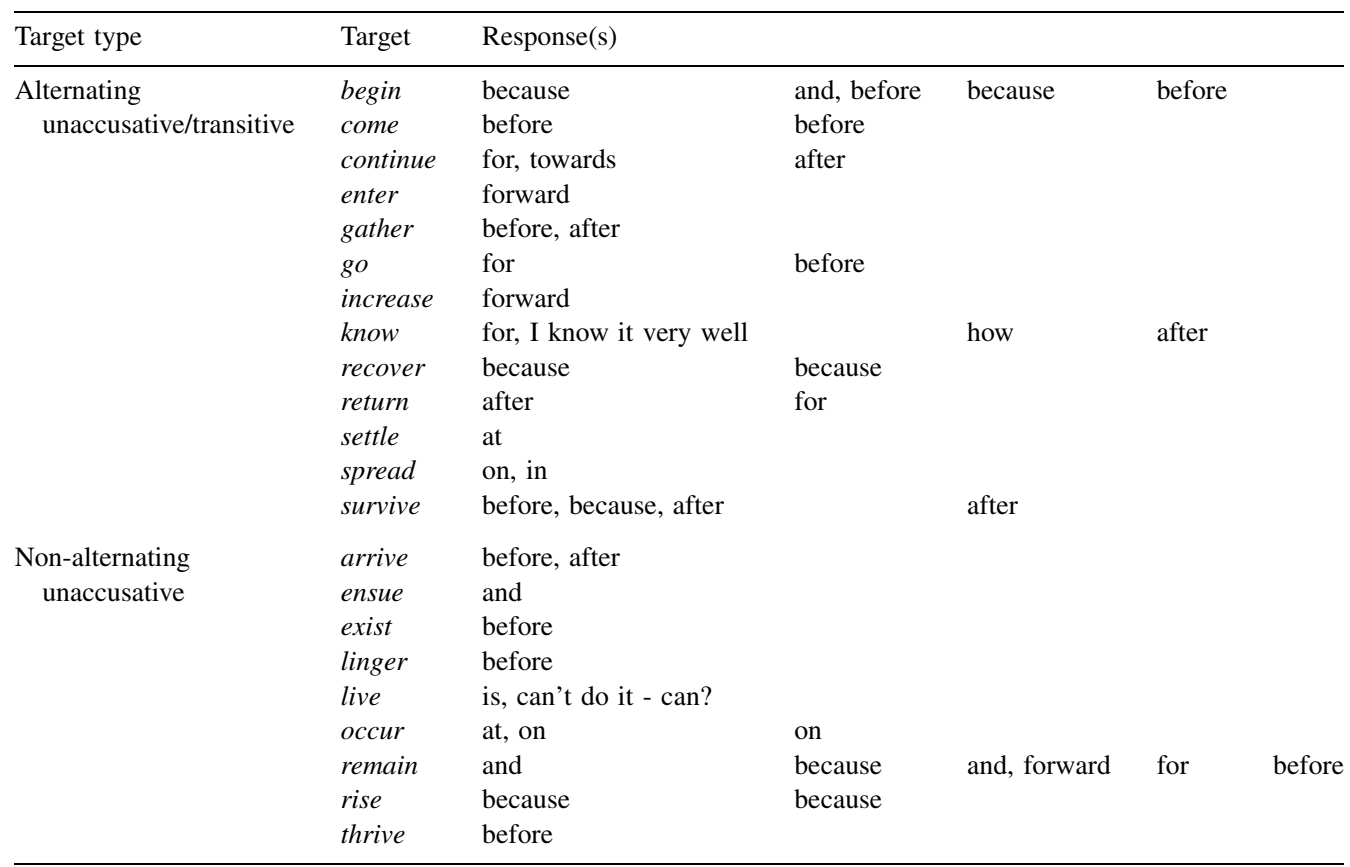

In other words, these data are not particularly amenable to a straightforward error analysis. Patterns within the data are not apparent. It seems that an explanation in terms of a less-than-total deficit, which yields an inconsistent pattern of responses, is the most plausible line of attackespecially in view of the fact that, when no transitive alternation is available, MC nevertheless reads non-alternating unaccusative verbs correctly around $70 \%$ of the time. MC makes function word substitution errors only when attempting to read function words; he never makes these kinds of errors when attempting to read substantives. His anomalous, and statistically significant, production of function word errors in response to written unaccusative verbs suggests that unaccusative syntax may, as proposed, involve an immediate requirement for some projection of a functional category. And it should be noted that MC does not make function word substitutions when reading inflected substantives (his errors on such items are usually errors of affixation, with stems being correctly produced), even though inflected (and even uninflected-e.g. Halle and Marantz, 1993) verbs and nouns are certainly associated with functional categories such as v, TNS, AGR, Asp, Num and so on. If MC only makes function word substitutions when a functional category is presented to him for reading, and if these errors do not extend to cases where a functional category is merely affixed to a substantive, then his function word errors on reading of unaccusative verbs are truly puzzling. 
In the following discussion, I will attempt to locate MC's performance within current theoretical accounts of the nature of unaccusativity. I will return to the view, presented earlier, that unaccusativity is the result of some (lexical) operation which changes the argument structure of an underlyingly transitive predicate. To account for MC's performance, I suggest that there is some functional realization of such verbs which is not overtly (morphophonologically) realized, and which does not involve simple affixation of a (phonetically null) functional morpheme to a substantive verb. For MC, the relation between the verb and the unaccusativizing functional morpheme could mean that unaccusative verbs are effectively realized as functional by the time they enter the syntactic derivation. MC's affixation errors result from a failure to recognize functional categories which project in the syntax - tense, agreement, number and so forth; his function word substitution errors, on the other hand, result from his misidentification of the whole item - stem, affix and whatever other material may be present - as a functional category. This could be straightforwardly captured under the assumption that lexically-implemented argument structure changes result in the presyntactic affixation of functional categories to substantives. In other words, I propose that MC's function word substitution errors on unaccusatives, like his other morphological errors, also result from errors of affixation; the only difference is that argument-structure changing affixation is presyntactic and results in a head category change (the lexical verb is adjoined to a functional head, resulting in MC's misidentification of the entire complex as functional).

\subsection{Other accounts of unaccusativity deficits in aphasia}

Several attempts have been made to capture the difficulties encountered by agrammatic aphasics when dealing with unaccusative verbs in various modalities. I will discuss here two of the most recent formulations of the unaccusativity problem in acquired language disorders.

Under a broadly Government and Binding approach, Kegl (1995) argued that sentential predicates involving unaccusative verbs should be as difficult for agrammatic aphasics to process as passives, because of the assumption that the presence of a surface subject with an Undergoer or Theme interpretation reflected movement of the verbs' single argument from the underlying object position. ${ }^{10}$ Empirical studies designed to determine whether Kegl's prediction was accurate (Gahl, 2002; Gahl et al., 2003) used sentence plausibility judgment tasks with a variety of aphasics and found that sentences involving unaccusatives were more likely to be processed appropriately than sentences involving passives. The authors took this as evidence that unaccusatives were not as difficult as passives in agrammatism, and they suggested that 'lexical bias' was a key factor-that is, the likelihood of a particular verb appearing in an unaccusative or passive construction in the language had more of an effect than the relative syntactic complexity of the stimulus. The Lexical Bias Hypothesis, as this approach was christened, does not capture MC's pattern of performance, mainly because it concerns the behavior of alternating verbs, and makes no prediction about non-alternating unaccusatives. To the extent that lexical bias information is available for the verbs used in this

\footnotetext{
${ }^{10}$ Nowadays, however, the single argument of both unaccusatives and unergatives is assumed to be generated in the domain of the VP and its interpretation is regulated by properties of the functional domain-the argument of an unergative being introduced by the (semi-)functional head $v$, while the argument of an unaccusative is determined by the lexical V (e.g. Arad, 1999; Embick, 2004). In such approaches, the differences (and similarities) between argument structure-related alternations - passives, reflexives, transitives, unaccusatives - are related to the feature specification of $v$.
} 
reading list (Gahl et al., 2004a,b), no correlation is apparent between the verbs on which MC made function word substitution errors and those which were more or less strongly biased towards being realized as unaccusatives. Kegl's proposal, which stresses the role of representational/derivational complexity in syntactically-based aphasic deficits, seems to provide a better account of MC's difficulties with these verbs (provided that her notion of syntactic complexity is taken in its broadest sense, to include lexical-semantic properties of verbs which project in the syntactic component, since the current task did not otherwise require $\mathrm{MC}$ to carry out any syntactic processing).

Thompson (2003) found that aphasic patients produced fewer unaccusative predicates in narratives, and in a picture-naming task, when compared to non-brain-damaged controls. They also performed better on comprehension tasks involving unaccusative constructions than they did on the production tasks. Thompson relates this performance to the initial characterization of agrammatic aphasia as primarily a production deficit, and suggests that complexity of argument structure representations may be the factor influencing production of various verb alternations for her aphasic subjects. The 'Argument Structure Complexity Hypothesis' holds that verbs with more arguments will be harder for agrammatics to produce than verbs with fewer arguments; additionally, verbs which have a non-canonical mapping between their argument structure requirements and their s-structure representations will also cause problems. This complexity metric does indeed predict with reasonable accuracy which categories of verbs MC had more difficulties with. It does not, however, explain why he sometimes treated particular categories, and not others, as if they have a functional representation.

\subsection{Accounting for MC's performance}

To summarize the discussion so far, unaccusatives are a subclass of intransitive verbs which have peculiar argument structure properties. I have considered two possible accounts of how these properties arise, and have suggested that unaccusatives are verbal predicates which have been modified by lexical adjunction to an argument-structure-changing functional head. This lexical operation has the effect of reducing the external argument of an underlyingly transitive predicate ('unaccusativization').

Because this external-argument-reducing morpheme is the head of the morphological representation of an unaccusative, MC misidentified the verb as functional when it was presented in isolation, making function word substitution errors because he was unable to assign a definite realization to functional items which are realized without the support of a syntactic frame. In effect, on the account I am proposing, unaccusative verbs are functional heads.

A problem remains: how is it that MC was able to read many unaccusative verbs correctly? He made many more function word substitution errors on unaccusatives than on other kinds of verbs; but he made far fewer function word substitution errors on unaccusatives than on other kinds of functional categories. What is it that allowed him to read these items correctly much of the time? I would suggest that, in the case of unaccusatives with a transitive alternation, the adjunction to a functional head is optional - at least when the verbs appear in isolation, as they did in this reading task. This would mean that the structure projected can either be the functional one, which incorporates the external-argument-reducing morpheme, or a straightforward extended projection with a lexical head (the transitive alternation). If MC carried out the lexical reduction operation, he made a function word error; if not, he was able to identify the stem correctly (as happened about $80 \%$ of the time)-though he still made other kinds of morphological errors involving overt affixation. 
The same kind of account can hold of verbs where no transitive alternation is available, given MC's propensity for omission and substitution of affixes. MC was able to read non-alternating verbs correctly, on this test, about two-thirds of the time. The fact that he was able to do this argues against Reinhart's (1997) suggestion that unaccusatives with no transitive alternation are lexically generated as 'frozen' in the unaccusative state (i.e. with a reduction operation having already applied to the external argument). His performance suggests that unaccusatives, at least for MC and perhaps for everyone, are really stored as transitives in the lexicon, even when no transitive alternation is available in a language. The obligatoriness of some unaccusative realizations could be a reflection of unaccusativity gradients, which vary cross-linguistically (cf. Sorace's, 1995, 2004). If MC was required to carry out a lexical operation every single time he had to produce an unaccusative, bearing in mind his deficits in other kinds of affixation and the frequency with which he omitted or substituted overtly realized morphemes, it should come as no surprise that he often failed to carry out operations involving affixation of phonologically null morphemes, too. When he did manage to associate $\mathrm{V}$ with the appropriate unaccusativizing head in the lexicon, he was liable to make function word substitution errors; when he failed to carry out this lexical operation, he was more likely to be able to identify the verb stem correctly-though he also made affixation errors in this case too, resulting in the kinds of affixation errors detailed in section 3.4.

This account of MC's performance predicts that he would sometimes have realized unaccusatives with different argument structure representations-so for example, unaccusative verbs should have been available for passivization in MC's system, at least some of the time. This prediction appeared to be somewhat supported by an examination of MC's transcribed spontaneous speech, which yielded the following examples involving the obligatorily unaccusative verb appear:
a. Also appeared the father.
b. They appeared the witches.
c. A little shoe was appeared.

(11a) seems to be an instance of failed realization of the unaccusativizing head in the syntax, so that the single remaining argument remains in its base position. ${ }^{11}$ (11b) has (at least) two possible interpretations, depending on whether the two arguments are coreferential are not; either MC mistakenly produced this verb as a reflexive (syntactic rather than lexical argument reduction, perhaps, in Reinhart and Siloni's, 2004 terms) or he produced a transitive alternation where this should be unavailable. (11c) is illegal passivization of an obligatorily unaccusative verb, resulting from erroneous affixation of an argument-structure-changing morpheme other than the unaccusativizing one-i.e. an affixation error entirely akin to the overt affixation errors seen in his single word reading.

\section{Conclusions}

MC was an aphasic man who made morphological errors in single word reading, and demonstrated a robust distinction in the type of errors between reading of substantives and

\footnotetext{
${ }^{11}$ Instances of deleted subjects are non-existent in MC's spontaneous speech; in fact, he uses expletive subjects quite often. Therefore, although (11a) could be viewed as a deleted expletive subject, this seems unlikely to be the case.
} 
reading of functional categories. Here I have reported on the errors he made when reading unaccusative verbs, which he seemed to treat as functional categories. Existing accounts of unaccusative verb production and processing in aphasia did not capture MC's performance, but by having recourse to current theoretical approaches to unaccusativity I provided a parsimonious account for MC's pattern of performance in this task. Finally, the interesting possibility is raised by this analysis, that his errors on function word reading are less distinct from his affixation errors on substantive reading than originally supposed: at least in the case of phonologically null argument-structure-changing morphemes, errors of affixation led to the production of typical function word substitution errors. Furthermore, and in keeping with the aim of a reciprocal relationship between clinical data and linguistic theory, the data obtained from MC's attempts to read alternating and non-alternating unaccusative verbs provide some support for a theoretical formulation of unaccusativity as the result of morphological operations involving lexical reduction of the external argument as a reflex of adjunction of a transitive verb to a functional head before the verb enters the numeration.

\section{Acknowledgments}

I am honoured to have an opportunity to thank two amazing people, both of whom it has been a great pleasure and privilege to have known and worked with. Neil Smith has been, and I hope always will be, a wonderful teacher and friend, a true joy to know, and a great influence in my life and work. MC, the aphasic man who made this work and much of my previous work possible through his kindness, hard work and humor in the face of quite severe physical and linguistic deficits, passed away in 2004. I thank them both, for more than they could know.

I also wish to thank Judit Druks, for many interesting discussions and ideas; Peter Gordon, for his helpful suggestions; Diane Blakemore, Susanne Gahl and two anonymous Lingua reviewers for their insightful comments and suggestions on earlier drafts of this paper. All remaining errors are my own.

\section{References}

Arad, M., 1999. On the nature of v: evidence form object experiencer verbs. Paper presented at GLOW 22, Berlin.

Baayen, R.H., Piepenbrock, R., Gulikers, L., 1995. The CELEX Lexical Database (Release 2CD-ROM). Linguistic Data Consortium, University of Pennsylvania, Philadelphia, PA.

Babyonyshev, M., Fein, R., Ganger, J., Pesetsky, D., Wexler, K., 2001. The maturation of grammatical principles: evidence from Russian unaccusatives. Linguistic Inquiry 32, 1-44.

Baker, M., Johnson, K., Roberts, I., 1989. Passive arguments raised. Linguistic Inquiry 20, 219-252.

Biassou, N., Obler, L.K., Nesopulous, J.L., Dordain, M., Harris, K.S., 1997. Dual processing of open and closed class words. Brain and Language 57, 360-373.

Borer, H., 2004. The grammar machine. In: Alexiadou, A., Anagnostopulou, E., Everaert, M. (Eds.), The Unaccusativity Puzzle: Explorations of the Syntax-Lexicon Interface. Oxford University Press, Oxford, pp. 288-331.

Burzio, L., 1986. Italian Syntax. A Government and Binding Approach. Reidel, Dordrecht.

Chomsky, N., 1965. Aspects of the Theory of Syntax. MIT Press, Cambridge, MA.

Chomsky, N., 1995. The Minimalist Program. MIT Press, Cambridge, MA.

Druks, J., Froud, K., 2002. The syntax of single words: evidence from a patient with a single word reading deficit. Cognitive Neuropsychology 19, 207-244.

Druks, J., Masterson, J., 2000. An Object and Action Naming Battery. Psychology Press, Hove, UK.

Embick, D., 2004. Unaccusative syntax and verbal alternations. In: Alexiadou, A., Anagnostopulou, E., Everaert, M. (Eds.), The Unaccusativity Puzzle: Explorations of the Syntax-Lexicon Interface. Oxford University Press, Oxford, pp. 137-158. 
Friederici, A.W., Schoenle, P.W., 1980. Computational dissociation of two vocabulary types: evidence from aphasia. Neuopsychologia 18, 11-20.

Froud, K., 2001a. Linguistic theory and language pathology: evidence for the morphology interface from a case of acquired language disorder. Unpublished Ph.D. dissertation. University College London.

Froud, K., 2001b. Prepositions and the lexical/functional divide: aphasic evidence. Lingua 111, 1-28.

Funnell, E., 1983. Phonological processes in reading: new evidence from acquired dyslexia. British Journal of Psychology 74, 159-180.

Gahl, S., 2002. Lexical biases in aphasic sentence comprehension: an experimental and corpus linguistic study. Aphasiology 16, 1173-1198.

Gahl, S., Jurafsky, D., Roland, D., 2004a. Verb subcategorization frequencies: American English corpus data, methodological studies, and cross-corpus comparisons. Behavior Research Methods, Instruments, and Computers 36, 432-443.

Gahl, S., Jurafsky, D., Roland, D., 2004b. Gahl2004norms.txt. Retrieved July 25th, 2004 from Psychonomic Society Web Archive: http://www.psychonomic.org /ARCHIVE/.

Gahl, S., Menn, L., Ramsberger, G., Jurafsky, D.S., Elder, E., Rewega, M., Holland, A.L., 2003. Syntactic frame and verb bias in aphasia: plausibility judgments of undergoer-subject sentences. Brain \& Cognition 53, 223-228.

Goodglass, H., Kaplan, E., 1972. The Assessment of Aphasia and Related Disorders. Lea \& Febiger, Philadelphia, PA.

Grimshaw, J., 1990. Argument Structure. MIT Press, Cambridge, MA.

Grodzinsky, Y., 1990. Theoretical Perspectives on Language Deficits. MIT Press, Cambridge, MA.

Halle, M., Marantz, A., 1993. Distributed morphology and the pieces of inflection. In: Hale, K., Keyser, S.J. (Eds.), The View from Building 20: Essays in Linguistics in Honor of Sylvain Bromberg. MIT Press, Cambridge, MA, pp. 111-176.

Howard, D., 1985. Agrammatism. In: Newman, S., Epstein, R. (Eds.), Current Perspectives in Dysphasia. Churchill Livingstone, Edinburgh, pp. 1-31.

Jakobson, R., 1956. Two aspects of language and two types of aphasic disturbances. In: Jakobson, R. (Ed.), Studies on Child Language and Aphasia, 1971. Mouton, The Hague/Paris, pp. 49-73.

Jaeggli, O., 1986. Passive. Linguistic Inquiry 17, 587-622.

Kaplan, E., Goodglass, H., Weintraub, S., 1983. The Boston Naming Test. Lea and Febiger, Philadelphia, PA.

Kay, J., Lesser, R., Coltheart, M., 1992. PALPA: Psycholinguistic Assessments of Language Processing in Aphasia. Lawrence Erlbaum Associates, Hove, UK.

Kegl, J., 1995. Levels of representation and units of access relevant to agrammatism. Brain and Language 50, 151-200.

Levin, B., Rappaport-Hovav, M., 1995. Unaccusativity: at the Syntax-Lexical Semantics Interface. MIT Press, Cambridge, MA.

Marshall, J.C., 1986. The description and interpretation of aphasic language disorder. Neuropsychologia $24,5-24$.

Montrul, S., 1999. Causative errors with unaccusative verbs in L2 Spanish. Second Language Research 15, $191-219$.

Morton, J., Patterson, K., 1980. Little words - no! In: Morton, M., Coltheart, M., Marshall, J.C. (Eds.), Deep Dyslexia. Routledge Kegan Paul, London, pp. 270-285.

Oshita, H., 2001. The unaccusative trap in second language acquisition. Studies in Second Language Acquisition 23, 279304.

Patterson, K., 1982. The relation between reading and phonological coding: further neuropsychological observations. In: Ellis, A.W. (Ed.), Normality and Pathology in Cognitive Functioning. Academic Press, London, pp. 71-111.

Pesetsky, D., 1995. Zero Syntax: Experiencers and Cascades. MIT Press, Cambridge, MA.

Reinhart, T., 1997. Syntactic effects of lexical operations: reflexives and unaccusatives. OTS Working Papers in Linguistics. University of Utrecht.

Reinhart, T., 2000. The Theta system: syntactic realization of verbal concepts. OTS Working Papers in Linguistics. University of Utrecht.

Reinhart, T., Reuland, E., 1993. Reflexivity. Linguistic Inquiry 24, 657-720.

Reinhart, T., Siloni, T., 2004. Against the unaccusative analysis of reflexives. In: Alexiadou, A., Anagnostopulou, E., Everaert, M. (Eds.), The Unaccusativity Puzzle: Explorations of the Syntax-Lexicon Interface. Oxford University Press, Oxford, pp. 159-180.

Snyder, W., Hymas, N., Crisma, P., 1995. Romance auxiliary selection with reflexive clitics: evidence for early knowledge of unaccusativity. In: Proceedings of the 26th Annual Child Language Research Forum, pp. 22-47.

Sorace, A., 1995. Acquiring linking rules and argument structures in a second language: the unaccusative/unergative distinction. In: Eubank, L., Selinker, L., Sharwood-Smith, M. (Eds.), The Current State of Interlanguage: Studies in Honor of William Rutherford. John Benjamins, Amsterdam, pp. 153-175. 
Sorace, A., 2004. Gradience at the lexicon-syntax interface: evidence from auxiliary selection and implications for unaccusativity. In: Alexiadou, A., Anagnostopulou, E., Everaert, M. (Eds.), The Unaccusativity Puzzle: Explorations of the Syntax-Lexicon Interface. Oxford University Press, Oxford, pp. 243-268.

Sorace, A., Shomura, Y., 2001. Lexical constraints in the acquisition of split intransitivity: evidence from L2 Japanese. Studies in Second Language Acquisition 23, 221-245.

Thompson, C.K., 2003. Unaccusative verb production in agrammatic aphasia: the argument structure complexity hypothesis. Journal of Neurolinguistics 16, 151-167. 